\title{
Presenting a Treatment Concept for People with a Self-Reported Sexual Interest in Children in an Outpatient Setting
}

\author{
Tina Schulz ${ }^{1}$, Simon Palmer1, Georg Stolpmann², Martina Wernicke1, Jürgen L. Müller ${ }^{1,2}$ \\ ${ }^{1}$ Asklepios Fachklinikum Göttingen, Göttingen, Germany \\ ${ }^{2}$ Department of Forensic Psychiatry and Psychotherapy, Georg-August-University Göttingen, Göttingen, Germany \\ Email: s.palmer@asklepios.com
}

How to cite this paper: Schulz, T., Palmer, S., Stolpmann, G., Wernicke, M. and Müller, J.L. (2017) Presenting a Treatment Concept for People with a Self-Reported Sexual Interest in Children in an Outpatient Setting. Open Journal of Psychiatry, 7, 1-17.

http://dx.doi.org/10.4236/ojpsych.2017.71001

Received: September 23, 2016

Accepted: November 30, 2016

Published: December 2, 2016

Copyright $\odot 2017$ by authors and Scientific Research Publishing Inc. This work is licensed under the Creative Commons Attribution International License (CC BY 4.0).

http://creativecommons.org/licenses/by/4.0/

c) (i) Open Access

\begin{abstract}
Results of several studies point to an increase in reported child sexual abuse offences in Germany and an even higher number of undetected cases are assumed. In addition, even more cases regarding the distribution of child pornography have been reported. On behalf of victims of child sexual abuse and for the general public, a preventive treatment approach for people with a sexual interest in children is of prime importance. Currently, there is no published, evaluated therapeutic approach for treating potential offenders, dark field offenders and bright field offenders with a sexual interest in children in an outpatient setting. We designed a cognitive-behavioral therapeutic approach that integrated need- and resource-oriented concepts for the specific treatment of those people. This treatment program comprises thirteen modules and is established for a period of about one and a half years. The therapy concept is presented in detail and we report experiences with two male clients. We found a reduction of child abusive behavior (on- and off-line), cognitive distortions and subjective psychological distress, an increase of the extent of self-perceived sexual self-regulation, life satisfaction and self-efficacy in general and a high level of clients' satisfaction with the therapy concept. The present therapy concept shows promising results as a potential viable treatment program to protect children by reaching out to people with a self-reported sexual interest in children in an outpatient setting, but further research is necessary.
\end{abstract}

\section{Keywords}

Prevention, Child Sexual Abuse, Child Pornography, Pedophilic Disorder, Therapy

\section{Introduction}

Deviant sexual interest represents one of the strongest determining factors in recidiv- 
ism among sexual offenders in general and among child sexual abusers (CSA) in particular [1] [2]. According to the DSM-5, pedophilic disorder is defined as "recurrent, intense sexually arousing fantasies, sexual urges, or behaviors involving sexual activity with prepubescent child or children over a period of at least six months, which causes marked distress or interpersonal difficulty or the individual has acted on these sexual urges" [3]. In samples of child pornography offenders (CPO) and CSA, a prevalence of pedophilic disorder of about $50 \%-65 \%$ was observed. This prevalence is much higher than in the general population [4] [5]. Pedophilic disorder and child sexual abuse offences are often conflated, but they are not synonymous. Some pedophiles have not committed child sexual abuse offences and some sex offenders with child victims do not meet the criteria of pedophilic disorder [6]. Pedophilic disorder is a medical term, whereas child sexual abuse is a legal term [7]. Therefore, a pedophilic disorder is neither a necessary nor a sufficient precondition for committing sexual offences against children [8].

In the Year 2012, 12,623 reported cases of child sexual abuse were recorded in Germany. Between the years 2011 and 2012, cases of sexual offences against children have increased by $1.4 \%$. Similarly, there was an increase in the distribution of child pornography by $3.7 \%$. In contrast, the possession and acquisition of child pornography have decreased by $16.9 \%$ [9].

It should be noted that statistics regarding sexual offences against children include only detected cases (bright field offences). However, a higher number of undetected cases (dark field offences) must be assumed [4]. An international comparison of 39 studies about child sexual abuse from 21 countries has shown estimated prevalence about $0 \%-53 \%$ sexual abuse of girls and $0 \%-60 \%$ sexual abuse of boys [10]. On behalf of victims of child sexual abuse and for the general public, a preventive treatment approach for people with a self-reported sexual interest in children is of prime importance.

The present therapy concept was developed and applied in an outpatient setting. Clients were people with a self-reported sexual interest in children, including those who are afraid of committing a first sexual crime (called: potential offenders), people who have already committed a sexual offence, unknown to the authorities (called: dark field offenders), as well as people with a pending criminal charge, during an ongoing investigation or after a sentence for sexual offence with children (called: bright field offenders).

Currently, there is no published, evaluated therapeutic approach for treating these groups of clients in an outpatient setting. In order to develop a new therapy concept, we reviewed several published approaches for stationary group treatment of sexual offender (Sex Offender Treatment Program, SOTP [11]; treatment program for sexual offenders, Behandlungs programmfür Sexualstrafttäter (BPS) [12], Rockwood Sexual Offenders' Treatment Program [13]). However, as these programs are not specifically designed for the treatment of child sexual abusers, and both SOTP and BPS only focus on clients' deficits, it seemed necessary to develop a new and integrated therapeutic approach. 


\section{The Therapy Concept}

The present therapy concept is a cognitive-behavioral therapeutic approach based on the SOTP, BPS, Rockwood Program and Good Lives Model (GLM) [14]. Additional aspects have been added from Dialectical Behavior Therapy (DBT) [15], Acceptance and Commitment-Therapy (ACT) [16], a manual for stress management [17], methods for cognitive reframing according to Wilken [18] as well as specific features in therapy of CPOs according to Quayle, Erooga, Wright, Taylor and Harbinson [19]. The GLM is a grounding therapeutic framework [20]. The main assumption of the GLM is that people commit offences because they are attempting to fulfill normal human needs or values like the need for affection or for community. Caused by their environment and their own deficits and weaknesses, offenders use criminal behavior to reach these goals. Hence, the therapy must equip such people with the skills, knowledge and resources necessary to satisfy their life values in pro-social ways. The present therapy concept is also based on the Risk-Need-Responsivity (RNR) model [21]. According to the risk principle, the treatment intensity should incorporate the offenders' risk of relapse. Therefore, we are providing additional therapy sessions if a client is at a higher risk. In line with the need principle, our therapy program is targeting typical risk factors like cognitive distortions, which give clients the permission for committing sexual crimes. According to the responsivity principle, the treatments are individually worked out to match the learning abilities of our clients.

The program consists of 13 modules, divided into 45 - 60 sessions of individual and group therapy. We have closed groups of five to nine members with session duration of 120 minutes, which take place three times a month. The individual therapy is delivered weekly with duration of 60 minutes.

Module 1: Motivation to Change/Group Constitution. The first module is used not only to increase the motivation to change and to define approach goals of the therapy, but also to build a therapeutic alliance between therapist and client as well as group cohesion. The most critical difference between individual and group therapy consists of the therapeutic use of some specific factors like group cohesion, trust, openness, support and modeling [22]. An exercise from the SOTP is used to initiate group cohesion. In line with the GLM, aspects of their lives that the clients want to change are explored in both the group and individual therapy. As life satisfaction prevents relapses [23], all important aspects of life from the clients' perspectives must be considered. According to Marshall and colleagues [24] our clients should call themselves people who have committed a crime instead of sexual offenders, because negative self-verbalizations cause feelings of shame, whereas statements like "I did something wrong" cause a feeling of guilt, which motivates change.

Module 2: Life History. The second module focuses on life history. The clients are asked to prepare their personal autobiography for the next therapy sessions by using a list of questions based on the BPS about important events from their family background, education, work, social contacts, relationship and sexual experiences. These life histories are presented by the clients in a group or individual therapy session. They are used for generating first hypotheses about the client's underlying needs that lead to offending according to the GLM approach. Thereby, we are minding a potential need for 
control behind a collection of child pornography material or a need for affiliation behind an exchange of child abusive pictures in a group of like-minded people [19]. In cases of potential offenders, the content of sexual fantasies with children or adolescents is used.

Module 3: Risk Factors. The next sessions are used for identifying the clients' relevant risk factors. Thus, we are working with the Finkelhor model [25] (see BPS and SOTP). On the basis of this model we identify and challenge the clients' cognitive distortions regarding child sexual abuse. According to Quayle et al. [19] it is important that CPOs understand, that images are children and that they actively support sexual abuse by watching child pornography material. Furthermore, so called seemingly unimportant decisions (according to the BPS) before the sexual crime are discussed and the use of helpful alternative decisions and behaviors are explored. Thereby, the clients establish more control over their behavior.

Module 4: Victim Empathy. After this, a module follows in which the clients learn to adopt the perspective of their (potential) victim(s) to increase victim empathy. Various studies found that sex offenders show primary empathy deficits towards their own victims (e.g. [26] [27]), which allow them to continue offending, as well as deficits in perception of others' emotions [28] and their own emotions [24]. Based on the model of empathic processes [29] our clients first learn to recognize emotional states of others, then to see things from the others' perspectives, followed by an appropriate emotional or compassionate response and finally to take steps to ameliorate others' distress. The module starts off by showing a documentary film about victims of natural disaster to practice emotional recognition in others and themselves. Afterwards, there is a group discussion which focuses on generating a list of consequences for victims of sexual assault by reading reports from victims (from BPS). Subsequently, clients are asked to think about the relevance of each of the listed consequences for their own victim(s). Here, it is important that CPO's recognize that the consequences for their online victims are still the same and the consumption of child pornography is as harmful as a hands-on offence. Furthermore, they should recognize that the unstoppable distribution of child abusive images over the Internet could cause lifelong abusive experiences for their victims, in which the clients are actively involved [19]. In the next sessions, clients perform role-plays in order to develop the ability to take the perspective of their own victims. If necessary, it can be helpful to ask clients to consider a hypothetical situation where a person they love is the victim of a sexual crime [24]. Finally, each client is required to write two hypothetical letters (see Rockwood Program or SOTP): one supposedly from the victim to the client and the other from themselves to the victim (they are not to be sent to the victims). Both letters are read out to the group and are discussed. Thereby, the focus is on taking full responsibility for the offence and the ability to cognitively and emotionally understand the victim's distress and consequences.

Module 5: Pathway I. The fifth module serves as a first therapy summary. Clients are asked to prepare an overview worksheet about their offence path way(s). They have to establish a connection between personal appreciable factors from their life history, their Finkelhor model, their seemingly unimportant decisions and cognitive distortions before their sexual offences and the consequences for their own victim(s). Subsequent- 
ly, the overview will be presented to the group or therapist. At this point, the clients should be able to identify cognitive distortions and seemingly unimportant decisions and the needs behind their offence(s), to take full responsibility for their crime(s) and to feel a sympathetic response for their victims.

Module 6: Self-Esteem. At the next step, we target the self-esteem of our clients to enhance the clients' belief in their capacity to change (e.g. [19]). Some literature indicates that people with low self-esteem underestimate their capacity to change and that they often give up in the face of minor obstacles (e.g. [30]). In addition, low self-esteem may increase the risk of reoffending because people often do not believe in their ability to cope with negative mood states and stress, which could cause a higher risk to reoffend (e.g. [31] [32] [33]). In addition to the Rockwood Program, this module integrates some exercises from Dialectical Behavior Therapy (DBT) to provide the clients with behavioral coping skills to effectively manage emotional dys-regulation and poor frustration tolerance. Furthermore, the clients learn to give and receive compliments and positively present themselves to others. A large part of this module includes cognitive reframing techniques. Therefore, the $\mathrm{ABC}$ model of Albert Ellis according to Wilken [18] is presented and practiced. These techniques then are used to challenge dysfunctional self concepts.

Module 7: Personal Consequences from Sexual Abuse Offences. Next, a SOTPmodule for personal consequences from sexual abuse offences follows. In this module, clients should consider positive and negative short- and long-term consequences of their offence(s). These considerations stimulate clients to realize that they were focusing only on short-term positive consequences (e.g. sexual satisfaction) when they committed their crime(s), but disregarded long-term negative consequences (e.g. losses, fear, guilt, preventing a happy relationship). The problem of direct satisfaction is explained. By making a list of consequences, clients learn the negative consequences and establish a further barrier against reoffending.

Module 8: Intimacy and Attachment Styles. Sexual offenders often have inadequate intimacy skills and poor attachment styles [34]. Module 8 targets these deficits. Adult attachment styles are identified and discussed. Differences between intimacy and sexuality are considered. Problems with loneliness are discussed and adequate relationship skills are built. Towards the end, we use hypothetical scenarios, for example different controversial situations in a relationship, in order to identify and differentiate constructive and dysfunctional communication behavior.

Module 9: Emotion Management and Problem-Solving. Based on the previous module, this module is aimed at developing and enhancing coping strategies to deal with negative emotional states. Sexual offenders often abuse substances (e.g. [35] [36]) and have problems in emotional and sexual self-regulation (e.g. [37]). They adopt an emotion-focused coping style [38] [39] or engage in avoidance-focused coping, including sex as a (first) coping strategy [40]. Therefore, our clients are taught in problemfocused coping according to the Rockwood Program and in stress management skills according to Kaluza [17]. An adaptation of the SORKC model [41] is introduced to enhance problem-solving skills. Furthermore, mindfulness (DBT) and ACT-techniques are established. 
Module 10: Sexuality (Normative \& Deviant). Sexual offenders are frequently reported to have deficits in knowledge about sexuality [24]. The next module is aimed at closing gaps in knowledge and change dysfunctional believes about sexuality. A section of psycho education is implemented to inform about sexual urges. The human sexual response cycle according to Masters and Johnson [41] is introduced and the connection between sexual frustration, lack of satisfaction in relationships and committing sexual crimes is illustrated. The differences between normative and deviant sexuality, as well as differences between fantasies and behavior are discussed in the group. After this, the development of deviant sexual interests is considered, as well as factors for maintaining and reinforcing offence behavior. At the end, according to the Rockwood Program, a behavioral modification technique (masturbatory reconditioning) is discussed. In contrast to Marshall and colleagues [23] we do not believe in a complete changing of deviant arousal patterns. However, clients with sexual interests in children and adults might benefit from the possibility of reinforcing sexual fantasies of adults and thereby weakening sexual fantasies of children. We hold the opinion that this technique does not eliminate their sexual interest in children.

Module 11: Pathway II. Module eleven consists of a second therapy summary (extension of module five) as a basis for a detailed and individual relapse prevention plan in module 12. The clients are asked to use and edit their overview from module five and add their individual consequences (module 7) to draw conclusions about their individual risk situations and how they can handle them. Results are presented and discussed in group or individual therapy sessions. At home, clients are asked to write a continuous text about their offence pathway to understand links, check their knowledge about the main risk concepts and keep them in mind. Furthermore, they are asked to use this text to prepare their relapse prevention plan.

Module 12: Relapse Prevention Plan. The relapse prevention plan should list the main risk situations, such as feelings, thoughts, fantasies, hobbies, jobs, persons and locations and how the client would handle them. Thereby, the clients should distinguish coping strategies they have mastered and strategies that need more practice. Thus, missing or dysfunctional coping strategies are identified and discussed. Sometimes clients have to handle difficult risk situations in fantasy to make sure that they are prepared for several situations. At the end, each client is assisted in generating a list of indicators (warning signs) that they may be moving toward a risk situation: one set that would alert them and one set that would be observable to others. At home, clients should keep a risk situations diary to be continuously sensitized and to become confident in using their coping strategies.

Module 13: Future Plans. As the relapse prevention plan cannot possibly identify all future risks, it is also important to help the client formulate goals for the future at the end of the therapy. These approach goals should help clients to build up alternative pro-social ways of living that are likely to enhance life satisfaction and thereby minimize the risk for (re)-offences. For example, an important issue is what the client will do with his leisure time. Often, our clients have had little in the way of constructive leisure pursuits prior to coming to us, which typically leads to the experience of boredom. Boredom appears to be a significant risk factor [42]. By helping our clients formulate a 
plan for the future that serves their interest in seeking a fulfilling life, optimism and enthusiasm are reinforced which increase the chance that they will adhere to this plan.

\section{Method}

We present two cases, one for the illustration of the process of individual therapy and another for the process of group therapy. Both clients gave a written declaration of informed consent.

The procedure started with up to ten pre-treatment diagnostic sessions. After that, the first six therapy modules were concluded before an intermediate measure took place. The post measurement was scheduled after the last therapy session. For case 2, we can also report data from a follow up measurement (one year after therapy). The study was approved by the local ethics committee.

\section{Measures}

Self-Efficacy Scale Related to Minors-Coping (SESM) [43]: The SESM C is a 20item Coping scale to assess beliefs about the ability to control their sexual urges regarding children. Higher scores indicate a higher perceived ability of sexual self-control.

High Risk Situation Test (HRST) [43], German version according to Neutze et al. [44] —on a 58-item scale rate their risk to (re)offend in different situations on a fivepoint Likert Scale from 1 (low) to 5 (extremely high). A minimum score of 58 points means the client recognizes no risk situation he has to avoid or cope with to avoid (re)offending, while a maximum score of 232 means the client perceives himself at risk in every situation.

Questionnaire about sexual fantasies and behavior (Fragebogenzusexuellen Phantasien und Verhaltensweisen, SPV)-The SPV is an unpublished inventory assessing the frequency of sexual contacts with children and adolescents, of consuming child and juvenile pornography for masturbation and of sexual fantasies with children and adolescents. It is also used for assessing the frequency of non-sexual contacts with children and adolescents and of non-sexual watching of children's programs. Clients have to report their frequency on a six-point Likert Scale from 1 (never) to 6 (daily) within the last six months.

Symptom Checklist-90-Revised (SCL-90-R) [45], German version according to Franke, 2000, [46]-The SCL-90-R is a 90 -item self-report symptom inventory to measure psychological symptoms and distress. The measure assesses psychological distress in terms of nine primary symptom dimensions (e.g. depression, anxiety, aggression, obsessive-compulsive) and three summary scores and is used as a screening measure of general psychiatric symptomatic distress. Internal consistency coefficients of .79 to .89 have been reported for clinical samples.

Questionnaire about life satisfaction (Fragebogenzur Lebenszufriedenheit, FLZ) [47] -Clients have to rate their subjective life satisfaction on a 7-point Likert Scale in different aspects of life (e.g. health situation, work and career, leisure time, own person, sexuality, relationship). Life satisfaction will be measured in terms of one global score (the higher the score, the higher the life satisfaction) and ten subscales. Internal consistency coefficients of 0.82 to 0.95 have been reported and validity is secured according to 
the authors.

Bumby Child Molest Scale (BCMS) [48], German version according to Feelgood, Schaefer \& Hoyer, [49]—The German version of the Bumby Child Molest Scale measures offence-supportive cognitions about children and sex with them (Cronbach's $\alpha=$ 0.95) with a 38 -item scale on a 4-point Likert Scale. Higher scores indicate more offence-supportive attitudes (called cognitive distortions). Results will be compared to a sample of 33 imprisoned child sexual abusers with a mean score of 76.8 ( $S D=18.97$, [50].

Aachen self-efficacy questionnaire (Aachener Selbstwirksamkeitsfragebogen, ASF, [51])-This inventory assesses the subjective perceived self-efficacy with 20 items on a 5-point Likert Scale. Thereby, a summary score and three subscale scores (self-efficacy in health, relationships, work) can be ascertained. Higher scores indicate a higher perception of self-efficacy. Internal consistency coefficients of 0.81 to 0.87 have been reported.

\section{Results}

\subsection{Case Study 1}

Case Study 1 is a late-30's Caucasian male, with average IQ, who has been diagnosed with dysthymic disorder (DSM-IV-TR, 300.4) and an incurable tumor disease. He consumed child and juvenile pornography, due to a current proceeding and the anxiety of being a threat for children and adolescents he sought help. The client was in a diminished mental health status, because he suffered from strong sense of inferiority, he brooded, was unemployed, in debt, unable to accept the rejection of a women he loved, had no techniques to cope with frustration and everyday stress, had only few social contacts and spent the most part of the day playing online games. Prior to attending therapy, pre-assessment findings showed that he had high levels of subjective psychological distress (SCL-90-R, $T_{G S I}=69$, see Table 1 for results), a low level of life satisfaction (FLZ, Stanine $=3$ ) and despite the current proceeding he was unable to stop child and juvenile pornography use completely (SPV, less than once a month within the last six months). On the other hand, the client experienced himself relatively self-efficient in general (ASF, score $=70 \%$ ), perceived a high ability to maintain sexual self-control $($ SESM-C, score $=68)$, perceived himself at low risk to reoffend $($ HRST, score $=73)$ and showed a very low level of cognitive distortions (BCMS, score $=53$ ).

Table 1. Results from the 2 case studies.

\begin{tabular}{cccccccccc}
\hline \multirow{2}{*}{ Case Study 1 } & SESM-C & HRST & \multicolumn{2}{c}{ SCL-90 } & BCMS & \multicolumn{2}{c}{ FLZ } & \multicolumn{2}{c}{ ASF } \\
\cline { 2 - 10 } & score & score & GSI & T $_{\text {GSI }}$ & score & score & stanine & score & PR \\
\hline Pre & 68 & 73 & 1.14 & 69 & 53 & 214 & 3 & 3.45 & $70 \%$ \\
Intermediate & 74 & 65 & 0.73 & 64 & 54 & 222 & 3 & 3.15 & $50 \%$ \\
Post & 77 & 62 & 0.57 & 61 & 55 & 259 & 5 & 4.1 & $100 \%$ \\
Case Study 2 & & & & & & & & & \\
Pre & 62 & 62 & 0.02 & 37 & 94 & $/$ & $/$ & $/$ & $/$ \\
Intermediate & 73 & 58 & 0.05 & 41 & 74 & 245 & 4 & 3.5 & $70 \%$ \\
Post & 72 & 77 & 0.02 & 37 & 57 & 272 & 6 & 3.5 & $70 \%$ \\
follow Up & 77 & 76 & 0.04 & 39 & 57 & 283 & 6 & 3.5 & $70 \%$ \\
\hline
\end{tabular}


At the beginning of therapy, the client did not have any hypothesis about why he was consuming child and juvenile pornography within the last two years. After the first therapy modules he analyzed that he has a preference for small, delicate women and by searching for adult pornography with such women he found and consumed female child pornography. However, it was not a sexual preference for children or adolescents per se which guided his consumption behavior, but the assumption: "The younger, the weaker. With weak girls, there is a higher probability that she needs me and that I can give her something despite my low self-esteem, my incurable tumor disease and bad financial situation". According to the GLM-approach, the client could identify a strong need for affiliation and appreciation behind his offence behavior. Therefore, one part of the therapy focused on finding pro-social ways to fulfill these needs. After identifying and changing dysfunctional cognitive schemata and cognitive distortions as well as learning to take the victims' perspective in role-play there were a lot of feelings of guilt and regret, so for stabilization module six for building up self-esteem was very important. The intermediate assessment findings showed no improvements in life satisfaction (FLZ, Stanine $=3$ ), but more satisfaction in aspects of social contacts (FLZ, from Stanine $=3$ to Stanine $=5$ ) and the client stopped consuming child und juvenile pornography completely (SPV). There was also an improvement in levels of subjective psychological distress (SCL-90-R, $T_{G S I}=64$ ), although these scores had been of clinical relevance. There was also an increase in the perceived ability to maintain sexual self-control (SESM-C, score $=74$ ), a decrease in the perceived risk to reoffend (HRST, score $=65$ ), whereby the level of cognitive distortions remained relatively stable (BCMS, score = 54). On the other side a decrease in the experienced self-efficacy in general (ASF, score $=50 \%$ ) was observed.

In the second part of therapy, the client realized that consuming child and juvenile pornography was a coping mechanism for occupational and emotional frustration, while other coping strategies were missing. He discerned that he had always had a feeling of inability to control his life originating from several negative experiences. He had had frustrating experiences in relationships, suffered from recurrences of his tumor disease, needed to be on welfare and got to hear from his father, that everything he did was not good enough. The client also realized that consuming child and juvenile pornography was an effort to find an aspect of life he could control. Therefore, it was necessary to spend a lot of work on finding and practicing new functional coping strategies and finding a new hobby that provides a feeling of control. In the end, the client used autogenic training, mindfulness exercises and ACT-exercises for relaxation from everyday stress and to calm himself down when he experienced frustration, was able to step back cognitively from dysfunctional thoughts and systematically analyzed his coping options and problem-solving skills. He also trained himself in accepting things he could not change instead of wasting resources by fighting against them (ACT-approach). He learned to improve his relationship skills and tried to enjoy social situations more often instead of isolating himself and wasting time in sullen brooding. He reactivated his old hobby of collecting and building up model railways. Towards the end of the therapy, he was able to cope with several cases of death in his family. His relapse prevention plan was very detailed and elaborate. He formulated realistic approach 
goals for the future. The post-assessment findings showed a marked improvement in life satisfaction (FLZ, Stanine $=5)$ with more satisfaction in aspects of personal health (FLZ, from Stanine $=1$ to Stanine $=4)$, work and career $(\mathrm{FLZ}$, from Stanine $=1$ to Stanine = 7), leisure time (FLZ, from Stanine $=6$ to Stanine = 7), own person (FLZ, from Stanine $=3$ to Stanine $=5)$ and sexuality (FLZ, from Stanine $=3$ to Stanine $=5)$. There was no relapse in consuming child pornography (SPV). Despite spending a lot of time on the Internet (like in the past), the client more often met with others, spent time enjoying a coffee in a café and building up model railways. There was also an improvement in levels of subjective psychological distress (SCL-90-R, $T_{G S I}=61$ ) and an increase in the perceived ability to maintain sexual self-control (SESM-C, score $=77$ ), a decrease in the perceived risk to reoffend (HRST, score $=62$ ), whereas the level of cognitive distortions remained relatively stable $(\mathrm{BCMS}$, score $=55)$. Also, the client experienced himself as very self-efficient in general (ASF, score $=100 \%$ ).

\subsection{Case Study 2}

Case Study 2 is anearly-50's Caucasian male, with average IQ, who has been diagnosed with pedophilic disorder (nonexclusive type, DSM-5, 302.2) and hebephilic preferences. The client reported never having experienced sexual intercourse or a stable relationship. The reason for his help-seeking behavior was anxiety about being a pedophile and consuming child and juvenile pornography. He was relieved to have been detected to consume child and juvenile pornography a year before, because he was scared about what would have happened, if he had not been detected (anxiety to commit a child sexual abuse).He remembered the time of the proceeding as the worst time of his life until he received a suspended sentence. At the beginning of the therapy, the client seemed to be very dissatisfied with his life (FLZ was not yet established at that time). He felt lonely because he had lost a lot of relatives in his life (mother committed suicide, father was never interested in him and an alcoholic, his mother's parents had an important educational influence on him). He had a lot of social contacts in a club, but did not trust anybody in a way that he could speak with them about his fears, worries and wishes. The client reported sexual contacts with his 16-years old niece many years ago, but did not see them as a kind of sexual offence. He had always suffered from being shy because he was scared of being rejected and disgracing himself. As he had known her since her birth, his niece was the only person he trusted and so he was able to initiate sexual contacts. At this point, the client believed that his niece wanted these sexual contacts as well and so he could not understand why she had spoken with her parents about them (some years later) leading to his sister and niece breaking contact to him. To him, it seemed that he had done something wrong when initializing sexual contacts to a person he liked and was punished with refusal and loneliness. Prior to attending therapy, pre-assessment findings showed that he had low levels of subjective psychological distress (SCL-90-R, $T_{G S I}=37$ see Table 1 for results), because he felt relieved at the end of the proceeding with a suspended sentence. The client perceived a great ability to maintain sexual self-control (SESM-C, score $=62$ ) and perceived himself at low risk of committing a hands-on sexual offence (HRST, score $=62$ ), but he had a very high level of cognitive distortions (BCMS, score $=94$ ). On the other hand, he reported 
daily fantasies of sexual contacts with children and adolescents (SPV), but did not consume child or juvenile pornography within the last six months, because he was still shocked by the proceeding. ASF was not yet established at that time.

The client was recommended participation in group therapy. He was initially hesitant to join the group because he was scared of opening up to others. After some sessions, he became more open; he enjoyed the support of the group members more and more as well as supporting them. He was always prepared for the therapy sessions and took part regularly. During the first part of therapy, the client realized that he used child and juvenile pornography to fulfill his need for affiliation and his need for control by collecting and sorting pornographic material. His shyness and fear of rejection prevented him from fulfilling these needs using different activities. Furthermore, he learned to identify cognitive distortions and seemingly unimportant decisions and modify them in an appropriate way. Thereby, he often helped other group members in identifying and modifying their own cognitive distortions. During the module victim empathy, the client learned not only to understand and feel what victims of sexual abuse think and feel but also to access his own emotions and share them with the group. He also understood the reason why his niece did not refuse sexual contact with him, but still suffered from them long-term. He analyzed that he exploited the trust of his niece, hurt her and recognized his guilt for losing her and her mother (his sister). It was difficult for him to understand, that he could not undo what had happened and he could not forgive himself for hurting people he loves. So again, the module self-esteem was necessary for stabilization. In this module, he received a lot of positive feedback and compliments from other group members and learned to value the positive things in his life and give them more attention. He was getting more active and learned to do something good for himself and seemed to be more satisfied with his life (FLZ, Stanine =4). The intermediate-assessment findings showed marked improvements in the level of cognitive distortions (BCMS, score $=74$ ) as well as improvements in the perceived ability to maintain sexual self-control (SESM-C, score $=73$ ) and a lower perceived risk for committing a hands-on sexual offence again (HRST, score $=58$ ). He experienced himself as relatively self-efficient in general (ASF, score $=70 \%$ ). His low feelings of psychological distress remained relatively stable (SCL-90-R, $T_{G S I}=41$ ). But within the first part of therapy he was unable to avoid consuming child and juvenile pornography completely and used it less frequently than once a month within the last six months again (SPV).

During the second part of therapy, the client especially benefited from the module dealing with emotions and problem-solving. He started to systematically analyze his problems and solve them. For example, after he had concluded that boredom, loneliness and losing himself in negative experiences and feelings were main risk situations for him, he started jaunting, thereby training mindfulness skills. In addition, he bought himself a camera for taking photos on his trips. He took a lot of time enjoying nature and editing his photos. Instead of collecting child and juvenile pornography material, he started watching historical documentaries and found a new task in writing online articles about them. To remind himself to never consuming child and juvenile pornography material again and to remind him of the what he has learned in therapy, he always 
takes his victim empathy letters with him and puts a note with a list of negative consequences for himself of committing a sexual offence again on his computer monitor. He has support from a friend and tries to enjoy more time in his club. He formulated a detailed relapse prevention plan and realistic approach goals for the future. Maybe because of discussing risk situations in detail at the end of therapy the post-assessment findings showed an increase in the perceived risk for committing a sexual offence again (HRST, score $=77)$. The perceived ability to maintain sexual self-control remained relatively stable (SESM-C, score $=72$ ), although the client used child and juvenile pornography material less than once a month within the last six months again (SPV). Again, he did not feel psychological distress (SCL-90-R, $T_{G S I}=37$ ) and he became more satisfied with his life (FLZ, from Stanine $=4$ to Stanine $=6$ ). At the end of therapy there was a marked improvement in the level of cognitive distortions (BCMS, score $=57$ ), which was well below the average score compared to a group of child sexual abusers (BCMS, $M=76.8$ ). His experience of self-efficacy in general remained stable (ASF, score = 70\%).

After the one year follow up, the client reported being fine, had used child or juvenile pornography material less than once a month again and had not committed any hands-on offences within the last six months (SPV). The one year follow up assessment showed a stable low level of cognitive distortions (BCMS, score $=57$ ), the experience of self-efficacy in general (ASF, score $=70 \%$ ), the perceived ability to maintain sexual self-control (SESM-C, score $=77$ ) and the perceived risk for committing a hands-on sexual offence (HRST, score $=76$ ). He did not feel psychological distress (SCL-90-R, $\left.T_{G S I}=39\right)$ again and feltsatisfied with his life (FLZ, Stanine $=6$ ).

\section{Discussion}

We designed a cognitive-behavioral therapeutic approach that integrates need- and resource-oriented concepts for the specific treatment of people with a self-reported sexual interest in children in an outpatient setting. This treatment program was presented and results of two cases were reported for illustration of the process of group and individual therapy. It could be observed that both clients improved across different outcome measures after completion of therapy. Furthermore, it can be noted that they are generally satisfied with the therapeutic contents. It can also be noted that both clients reduced child abusive behavior (on- and off-line) and benefited concerning co-morbid disorders and problems. Thus, positive outcomes could be observed regarding undetected and detected sexual abuse offences. The therapy concept is aimed at bright field offenders besides dark field offenders to effectively reduce child abusive behavior.

Overall, the present therapy concept shows promising results as a potentially viable treatment program for protecting children by reaching out to people with a self-reported sexual interest in children in an outpatient setting. Furthermore, this study showed that this therapy concept can be effective in decreasing the risk of sexual recidivism; however caution should be taken as only two case studies were involved.

\section{Limitations}

Given that we only report data from two cases, the findings are largely tentative and not 
to be generalized. Further research on the effectiveness of this program, preferably with a larger sample size and a control group, is needed. Based on the general framework, using a waiting group seems difficult from an ethical standpoint as the help-seeking people with a risk to sexually (re-)offend would have to wait over a period of one and a half year without any specific treatment. Another limitation is, that we had to trust the information our clients gave us as we had no official records of the clients' criminal history.

\section{Recommendations}

The presented findings point at the potential efficacy of our cognitive-behavioral treatment for treating CSA as well as CPO. Further research is needed to explore the differential effectiveness of the different components (e.g. DBT skills training, ACT exercises) for people with a self-reported sexual interest in children. In the future, we plan to use more specific instruments in order to get more detailed information about child pornography use or specific coping styles. For example, boredom and loneliness are assumed to be important predictors of child pornography use [52] [53]. Furthermore, a group of online offenders (the majority were convicted of child pornography offences), who recidivated with a sex crime, more often committed a new child pornography offence than a contact offence [5]. Thus, the analysis of specific changes, for example in frequency and the kind of child pornography use, is important.

Currently, we are working on the proving of further assessment measures. Thus, we are using the Empathy for Children Scale (ECS) [54], and a modified version of the Therapist Rating Scale (TRS-10, German version according to Fuchs, Berner \& Briken, $2013[55])$.

\section{Acknowledgements}

We acknowledge support by the Open Access Publication Funds of the Göttingen University.

\section{References}

[1] Hanson, R.K. and Bussière, M.T. (1998) Predicting Relapse: A Meta-Analysis of Sexual Offender Recidivism Studies. Journal of Consulting and Clinical Psychology, 66, 348-362. https://doi.org/10.1037/0022-006X.66.2.348

[2] Hanson, R.K. and Morton-Bourgon, K.E. (2005) The Characteristics of Persistent Sexual Offenders: A Meta-Analysis of Recidivism Studies. Journal of Consulting and Clinical Psychology, 73, 1154-1163. https://doi.org/10.1037/0022-006X.73.6.1154

[3] American Psychiatric Association (2013) Diagnostic and Statistical Manual of Mental Disorders. 5th Edition, Washington DC.

[4] Seto, M.C. (2008) Pedophilia and Sexual Offending against Children: Theory, Assessment, and Intervention. American Psychological Association, Washington DC. https://doi.org/10.1037/11639-000

[5] Seto, M.C., Hanson, R.K. and Babchishin, K.M. (2011) Contact Sexual Offending by Men with Online Sexual Offences. Sexual Abuse: A Journal of Research and Treatment, 23, 124145.

[6] Seto, M.C. (2009) Pedophilia. The Annual Review of Clinical Psychology, 5, 391-407. 
https://doi.org/10.1146/annurev.clinpsy.032408.153618

[7] Mokros, A., Osterheider, M. and Nitschke, J. (2012) Pädophilie: Prävalenz, Ätiologie und Diagnostik. Der Nervenarzt, 83, 55-358. https://doi.org/10.1007/s00115-011-3322-7

[8] Schaefer, G.A., Mundt, I.A., Feelgood, S. and Beier, K.M. (2010) Potential and Dunkelfeld Offenders: Two Neglected Target Groups for Prevention of Child Sexual Abuse. International Journal of Law and Psychiatry, 33, 154-163. https://doi.org/10.1016/j.ijlp.2010.03.005

[9] Bundeskriminalamt (2014) Polizeiliche Kriminalstatistik 2012. http://www.bka.de/nn_196106/DE/Publikationen/PolizeilicheKriminalstatistik/pks__node. html? _nnn=true

[10] Pereda, N., Guilera, G., Forns, M. and Gomez-Benito, J. (2009) The International Epidemiology of Child Sexual Abuse: A Continuation of Finkelhor (1994). Child Abuse \& Neglect, 33, 331-342. https://doi.org/10.1016/j.chiabu.2008.07.007

[11] Fuchs, A. and Mann, R. (2007) Das Sex Offender Treatment Programme (SOTP) in England und Wales. In: Berner, W., Briken, P. and Hill, A., Eds., Sexualstraftäter behandeln mit Psychotherapie und Medikamenten, Deutscher Ärzte-Verlag, Köln, 33-45.

[12] Wischka, B., Foppe, E., Griepenburg, P., Nuhn-Naber, C. and Rehder, U. (2004) Das Behandlungsprogramm für Sexualstraftäter (BPS). Kriminalpädagogischer Verlag, Lingen.

[13] Marshall, W.L., Marshall, L.E., Serran, G.A. and Fernandez, Y.M. (2006) Treating Sexual Offenders: An Integrated Approach. Routledge, New York.

[14] Ward, T. and Stewart, C.A. (2003) The Treatment of Sex Offenders: Risk Management and Good Lives. Professional Psychology. Research and Practice, 34, 353-360. https://doi.org/10.1037/0735-7028.34.4.353

[15] Bohus, M. and Wolf, M. (2009) Interaktives Skillstraining für Borderline-Patienten. Schattauer, Stuttgart.

[16] Flaxman, P.E., Blackledge, J.T. and Bond, F.W. (2014) Akzeptanz- und CommitmentTherapie. Junfermann Verlag, Paderborn.

[17] Kaluza, G. (2009) Stressbewältigung. Trainingsmanual zur psychologischen Gesundheitsförderung. Springer Medizin Verlag, Berlin.

[18] Wilken, B. (2013) Methoden der kognitiven Umstrukturierung: Ein Leitfaden für die psychotherapeutische Praxis. W Kohlhammer, Stuttgart.

[19] Quayle, E., Erooga, M., Wright, L., Taylor, M. and Harbinson, J. (2006) Only Pictures? Therapeutic Work with Internet Sex Offenders. Russell House, Dorsit.

[20] Yates, P.M., Prescott, D. and Ward, T. (2010) Applying the Good Lives and Self-Regulation Models to Sex Offender Treatment: A Practical Guide for Clinicians. Safer Society Press, Brandon.

[21] Andrews, D.A. and Bonta, J. (2007) The Risk-Need-Responsivity Model of Assessment and Human Service in Prevention and Corrections: Crime-Prevention Jurisprudence. The Canadian Journal of Criminology and Criminal Justice, 49, 439-464. https://doi.org/10.3138/cjccj.49.4.439

[22] Hautzinger, M. (2011) Kognitive Verhaltenstherapie: Behandlung psychischer Störungen im Erwachsenenalter. Beltz Psychologie Verlags Union, Weinheim.

[23] Marshall, W.L., Serran, G.A., Marshall, L.E. and Moulden, H. (2001) Application for Accreditation of the Rockwood Sexual Offenders' Treatment Program. Rockwood Psychological Services, Kingston.

[24] Finkelhor, D. (1984) Child Sexual Abuse: New Theory and Research. The Free Press, New York.

[25] Fernandez, Y.M. and Marshall, W.L. (2003) Victim Empathy, Social Self-Esteem and Psychopathy in Rapists. Sexual Abuse, 15, 11-26. 
[26] Fernandez, Y.M., Marshall, W.L., Lightbody, S. and O’Sullivan, C. (1999) The Child Molester Empathy Measure: Description and an Examination of Its Reliability and Validity. Sexual Abuse, 11, 17-31.

[27] Hudson, S.M., Marshall, W.L., Wales, E., McDonald, E., Bakker, L.W. and McLean, A. (1993) Emotional Recognition Skills of Sex Offenders. Annals of Sex Research, 6, 199-211. https://doi.org/10.1177/107906329300600303

[28] Marshall, W.L., Hudson, S.M., Jones, R.L. and Fernandez, Y.M. (1995) Empathy in Sex Offenders. Clinical Psychology Review, 15, 99-113. https://doi.org/10.1016/0272-7358(95)00002-7

[29] Baumeister, R.F. (1993) Self-Esteem: The Puzzle of Low Self-Regard. Springer, Berlin. https://doi.org/10.1007/978-1-4684-8956-9

[30] Hanson, R.K. and Thornton, D. (2000) Improving Risk Assessments for Sex Offenders: A Comparison of Three Actuarial Scales. Law and Human Behavior, 24, 119-136. https://doi.org/10.1023/A:1005482921333

[31] Serran, G.A. and Marshall, W.L. (2005) The "Memory Recovery Technique": A Strategy to Improve Recall of Offence-Related Details in Men Who Commit Sexual Offences. Clinical Case Studies, 4, 3-12. https://doi.org/10.1177/1534650103259672

[32] Thornton, D., Beech, A. and Marshall, W.L. (2004) Pre-Treatment Self-Esteem and PostTreatment Sexual Recidivism. International Journal of Offender Therapy and Comparative Criminology, 48, 587-599. https://doi.org/10.1177/0306624X04265286

[33] Marshall, W.L. (1993) The Role of Attachment, Intimacy, and Loneliness in the Etiology and Maintenance of Sexual Offending. Sexual and Marital Therapy, 8, 109-121. https://doi.org/10.1080/02674659308408187

[34] Abracen, J., Looman, J. and Anderson, D. (2000) Alcohol and Drug Abuse in Sexual and Nonsexual Violent Offenders. Sexual Abuse, 12, 263-274. https://doi.org/10.1177/107906320001200403

[35] Seto, M.C. and Barbaree, H.E. (1995) The Role of Alcohol in Sexual Aggression. Clinical Psychology Review, 15, 545-566. https://doi.org/10.1016/0272-7358(95)00033-L

[36] Ward, T. and Hudson, S.M. (2000) A Self-Regulation Model of Relapse Prevention. In: Laws, D.R., Hudson, S.M. and Ward, T., Eds., Remaking Relapse Prevention with Sex Offenders. A Sourcebook, Sage, Thousand Oaks, 79-101. https://doi.org/10.4135/9781452224954.n5

[37] Marshall, W.L., Cripps, E., Anderson, D. and Cortoni, F.A. (1999) Self-Esteem and Coping Strategies in Child Molesters. Journal of Interpersonal Violence, 14, 955-962. https://doi.org/10.1177/088626099014009003

[38] Marshall, W.L., Serran, G.A. and Cortoni, F.A. (2000) Childhood Attachments, Sexual Abuse, and Their Relationship to Adult Coping in Child Molesters. Sexual Abuse, 12, 17 26. https://doi.org/10.1177/107906320001200103

[39] Cortoni, F. and Marshall, W.L. (2001) Sex as a Coping Strategy and Its Relationship to Juvenile Sexual History and Intimacy in Sexual Offenders. Sexual Abuse, 13, 27-43

[40] Kanfer, F.H., Reinecker, H. and Schmelzer, D. (2000) Selbstmanagement-Therapie. Springer, Berlin. https://doi.org/10.1007/978-3-662-09851-6

[41] Masters, W.H. and Johnson, W.E. (1970) Human Sexual Inadequacy. Little Brown Co., Boston.

[42] Pithers, W.D., Beal, L.S., Armstrong, J. and Petty, J. (1989) Identification of Risk Factors through Clinical Interviews and Analysis of Records. In: Laws, D.R., Ed., Relapse Prevention with Sex Offenders, Guilford Press, New York, 77-87.

[43] Marques, J.K., Day, D.M., Nelson, C., Miner, M. and West, M.A. (1991) The Sex Offender 
Treatment and Evaluation Project: Fourth Report to the Legislature in Response to PC 1365. California State Department of Mental Health, Sacramento.

[44] Neutze, J., Seto, M.C., Schaefer, G.A., Mundt, I.A. and Beier, K.M. (2011) Predictors of Child Pornography Offences and Child Sexual Abuse in a Community Sample of Pedophiles and Hebephiles. Sexual Abuse, 23, 212-242.

[45] Derogatis, L.R. (1994) Symptom Checklist-90-R: Administration, Scoring \& Procedure Manual for the Revised Version of the SCL-90. National Computer Systems, Minneapolis.

[46] Franke, G.H. (2000) Brief Symptom Inventory von Derogatis. Kurzform der SCL-90-R (BSI), Beltz Test, Göttingen.

[47] Fahrenberg, J., Myrtek, M., Schumacher, J. and Brähler, E. (2000) Fragebogen zur Lebenszufriedenheit (FLZ): Handanweisung. Hogrefe, Göttingen.

[48] Bumby, K.M. (1996) Assessing the Cognitive Distortions of Child Molesters and Rapists: Development and Validation of the MOLEST and RAPE Scales. Sexual Abuse, 8, 37-54.

[49] Feelgood, S., Schaefer, G.A. and Hoyer, J. (2008) KV-M Skala zur Erfassung kognitiver Verzerrungen bei Missbrauchern. Technische Universität, Dresden.

[50] Rambow, J., Elsner, K., Feelgood, S. and Hoyer, J. (2008) Einstellung zum Kindesmissbrauch. Zeitschrift für Sexualforschung, 21, 341-355. https://doi.org/10.1055/s-0028-1098723

[51] Wälte, D., Ludwig-Becker, F., Brandenburg, U., Saß, H., Petzold, E. and Kröger, F. (2000) Veränderung der kognitiven Selbstregulation bei Patienten mit psychosomatischen Störungen im Verlauf von stationärer Psychotherapie-eine kontrollierte Studie. In: Bassler, M., Ed., Leitlinien zur stationären Psychotherapie-Pro und Contra, Mainzer Werkstatt über empirische Forschung von stationärer Psychotherapie 1999, Psychosozial-Verlag, Gießen, 335-362.

[52] Chaney, M.P. and Chang, C.Y. (2005) A Trio of Turmoil for Internet Sexually Addicted Men Who Have Sex with Men: Boredom Proneness, Social Connectedness, and Dissociation. Sexual Addiction \& Compulsivity, 12, 3-18. https://doi.org/10.1080/10720160590933671

[53] Yoder, V.C., Virden, T.B. and Amin, K. (2005) Internet Pornography and Loneliness: An Association? Sexual Addiction \& Compulsivity, 12, 19-44. https://doi.org/10.1080/10720160590933653

[54] Schaefer, G.A. and Feelgood, S. (2010) Empathy for Children Scale. In: Fisher, T.D., Davis, C.M., Yarber, W.L. and Davis, S.L., Eds., Handbook of Sexuality-Related Measures, 3rd Edition, Routledge, New York, 7-11.

[55] Fuchs, A., Berner, W. and Briken, P. (2013) Deutsche Fassung der Therapist-Rating-Scale10. Forensische Psychiatrie, Psychologie, Kriminologie, 7, 44-46. https://doi.org/10.1007/s11757-012-0190-3 


\section{Abbreviations}

ACT: Acceptance and Commitment-Therapy [16]

ASF: Aachen self-efficacy questionnaire (Aachener Selbstwirksamkeitsfragebogen) [51]

BCMS: Bumby Child Molest Scale [48]

BPS: Behandlungsprogramm für Sexualstrafttäter [12]

CPO: child pornography offenders

CSA: child sexual abusers

DBT: Dialectical Behavior Therapy [15]

FLZ: Questionnaire about life satisfaction (Fragebogen zur Lebenszufriedenheit) [47]

GLM: Good Lives Model [14]

HRST: High Risk Situation Test [43]

RNR: Risk-Need-Responsivity model [21]

SCL-90-R: Symptom Checklist-90-Revised [45]

SESM: Self-Efficacy Scale Related to Minors - Coping [43]

SOTP: Sex Offender Treatment Program [11]

SPV: Questionnaire about sexual fantasies and behavior (Fragebogen zu sexuellen

Phantasien und Verhaltensweisen)

Submit or recommend next manuscript to SCIRP and we will provide best service for you:

Accepting pre-submission inquiries through Email, Facebook, LinkedIn, Twitter, etc. A wide selection of journals (inclusive of 9 subjects, more than 200 journals)

Providing 24-hour high-quality service

User-friendly online submission system

Fair and swift peer-review system

Efficient typesetting and proofreading procedure

Display of the result of downloads and visits, as well as the number of cited articles

Maximum dissemination of your research work

Submit your manuscript at: http://papersubmission.scirp.org/

Or contact ojpsych@scirp.org 